\title{
POLÍTICAS PÚBLICAS DE SAÚDE PARA IDOSOS COM ALZHEIMER ${ }^{1}$
}

PUBLIC HEALTH POLICIES FOR THE ELDERLY WITH ALZHEIMER'S DISEASE POLÍTICAS DE SALUD PÚBLICA PARA LOS ANCIANOS CON ALZHEIMER

Célia Barbosa Abreu²

Eduardo Manuel Val ${ }^{3}$

1 Este artigo é resultado de pesquisas realizadas junto ao Grupo de Pesquisa de Direitos Fundamentais, vinculado ao Diretório de Grupo do CNPQ, que conta com a participação de docentes, mestres e mestrandos do Mestrado em Direito Constitucional da Universidade Federal Fluminense (PPGDC/UFF), dentre outros colaboradores.

2 Doutora e Mestre em Direito Civil pela Universidade do Estado do Rio de Janeiro / UERJ. Professora do Programa de Pós-Graduação Stricto Sensu em Direito Constitucional - PPGDC / UFF. Professora Adjunta de Direito Civil da Faculdade de Direito da Universidade Federal Fluminense / UFF. Niterói. Rio de Janeiro. Brasil. celiababreu@terra.com.br .

3 Doutor e Mestre em Direito Público pela Pontifícia Universidade Católica do Rio de Janeiro / PUC RJ. Professor do Programa de Pós-Graduação Stricto Sensu em Direito Constitucional - PPGDC / UFF. Professor Adjunto de Direito Constitucional Internacional da Faculdade de Direito da Universidade Federal Fluminense / UFF. Professor do Programa de Pós-Graduação em Direito - PPGD / Universidade Estácio de Sá / UNESA. Niterói. Rio de Janeiro. Brasil. eduardval11@hotmail.com . 
Resumo: Contemporaneamente, nota-se a ocorrência do envelhecimento populacional mundial, que é visto como um dos principais ganhos sociais do século $\mathrm{XX}$, mas também como um fator de risco para o desenvolvimento global. Mundialmente, por conseguinte, percebe-se a imprescindibilidade de políticas públicas voltadas para os idosos. Mais do que isso, com o atual e constante crescimento da expectativa de vida da população, tem início a preocupação relativamente ao número de pessoas afetadas por doenças relacionadas à idade, como é o caso do mal de Alzheimer, que deverá aumentar drasticamente nos próximos anos. Tornase, pois, assunto da ordem do dia a discussão sobre as políticas públicas de saúde para os idosos, com foco específico na questão da doença de Alzheimer, principal causa de demência da pessoa idosa. Neste sentido, o presente trabalho consiste numa pesquisa teórica, que se utiliza dos métodos indutivo e comparatístico.

Palavras-chave: Envelhecimento mundial. Políticas públicas de saúde para idosos. Demência. Mal de Alzheimer.

Abstract: The ageing of world population is seen as one of the greatest social accomplishments of the 20th Century, but also as a risk factor for global development. As a result, public policies aimed at the elderly are more necessary than ever before. Even more so, the constant growth in life expectancy of the population is leading to concerns over the number of people affected by agerelated diseases, such as Alzheimer's disease, which is expected to increase drastically in the coming years. It is therefore essential to address the subject of public health policies for the elderly, focusing specifically on Alzheimer's disease, the leading cause of dementia among the elderly. This work consists of a theoretical study that uses the inductive and comparative methods.

Keywords: Global ageing. Public health policies. Elderly. Dementia. Alzheimer's disease.

Resumen: En los días actuales se observa la ocurrencia del envejecimiento de la población mundial, que es visto como una de las principales ganancias sociales del siglo XX, pero también como 
un factor de riesgo para el desarrollo global. Mundialmente, por consiguiente, se percibe la necesidad imprescindible de políticas públicas dirigidas a los ancianos. Más que eso, con el actual y constante crecimiento de la expectativa de vida de la población empieza la preocupación relativa al número de personas afectadas por enfermedades relacionadas a la edad, como es el caso del mal de Alzheimer, que deberá aumentar drásticamente en los próximos años. De esta manera, se vuelve asunto del orden del día la discusión sobre las políticas de salud pública para los ancianos, con foco específico en la cuestión de la enfermedad de Alzheimer, principal causa de demencia en las personas mayores. En este sentido, el presente trabajo consiste en una investigación teórica que utiliza los métodos inductivo y comparativo.

Palabras clave: Envejecimiento mundial. Políticas públicas de salud para ancianos. Demencia. Mal de Alzheimer.

\section{INTRODUÇÃO}

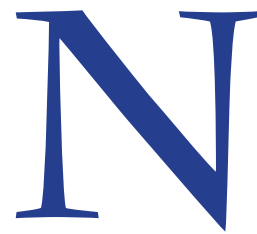
ão são de hoje as tentativas de prolongar a juventude, restaurar o vigor sexual e a vitalidade física. Os esforços para viver mais, no entanto, trazem consigo riscos próprios, sendo possível afirmar, de acordo com a mitologia grega, que o risco pode vir a ser maior do que o ganho. Alguns mitos trazem verdadeiras lições sobre o envelhecimento. Sobre os riscos de viver mais, por exemplo, interessante se lembrar do mito de Eos e Tithonus, sem se esquecer, por outro lado, do mito das famosas fontes Mnemósine (memória) e Lethe (esquecimento), em que os deuses e os mortais podiam se abeberar. ${ }^{4}$

Vive-se atualmente o envelhecimento populacional mundial, que é visto como um dos principais ganhos sociais do século $X X$, mas identificado como um fator de risco para o desenvolvimento global. Mundialmente, percebe-se a necessidade de políticas públicas voltadas para a saúde dos idosos, com foco na demência, doença bastante comum na terceira idade. Destaca-se a imprescindibilidade de conferir 4 BUSSE, Ewald W. O mito, história e ciência do envelhecimento. In: BUSSE, Ewald W.; BLAZER, Dan G (Org.). Psiquiatria geriátrica. Tradução de Maria Cristina Monteiro Goulart. Porto Alegre: Artes Médicas, 1992, passim. 
atenção especial ao Alzheimer, principal causa de demência da pessoa idosa.

A respeito desta temática, desenvolve-se o presente artigo em quatro partes. $A$ primeira cuida do envelhecimento; a segunda analisa o Alzheimer; a terceira traz um relato das políticas públicas de saúde internacionais e nacionais destinadas aos idosos; a quarta trata das políticas públicas de saúde internacionais e nacionais para idosos com Alzheimer. Na conclusão, se tem o espaço para comentários e críticas dos autores relativamente ao quadro das políticas públicas brasileiras de saúde dos idosos e à imperiosa urgência da adoção de um plano nacional de combate ao Alzheimer.

Uma vez que o trabalho consiste em uma pesquisa teórica, utilizou-se como parâmetro de produção a metodologia indutiva e comparativa para a consecução dos fins pretendidos e ora apresentados.

\section{ENVELHECIMENTO}

O aumento da expectativa de vida da população mundial, nas últimas décadas, tornou o envelhecimento um óbice universal. Este fato determinou a necessidade de que, paralelamente às modificações demográficas em curso, ocorram transformações socioeconômicas profundas, a fim de se conquistar a melhor qualidade de vida para os idosos, bem como para aqueles que estão envelhecendo. Nos países em desenvolvimento, esta meta está longe de ser concretizada, uma vez que, além de serem economicamente dependentes de outros países, detém uma estrutura socioeconômica arcaica, que privilegia uma minoria em detrimento da maioria. ${ }^{5}$

Diante do exposto, o Brasil necessitará fazer pesados investimentos na área de saúde, em especial, para atendimento da população idosa. Importante seguir a orientação da Organização Pan-Americana de Saúde, no sentido de se empreender um conjunto de ações que provoquem mudanças no estilo de

5 SHOUERI JUNIOR, Roberto; RAMOS, Luiz Roberto; PAPALÉO NETTO, Matheus. Crescimento populacional: aspectos demográficos e sociais. In: CARVALHO FILHO, Eurico Thomaz; PAPALÉO NETTO, Matheus (Org.). Geriatria: fundamentos, clínica e terapêutica. São PauIo: Atheneu, 2000, p.26. 
vida, objetivando a diminuição do risco de adoecer e morrer, estabilizando ou melhorando a saúde dos indivíduos em sua totalidade, aliando à saúde física a sua complexidade social. Estratégias devem ser realizadas para atingir estas metas nos campos psicossocial, político e econômico. ${ }^{6}$

Normalmente, o termo envelhecimento vinha associado ao declínio da eficiência/desempenho, doenças e morte. Era comum o preconceito com o idoso. Esquecia-se de que o envelhecimento também pode expressar modos desejáveis de amadurecimento. Algumas alterações etárias são benignas, contribuem para o desenvolvimento humano, a satisfação de suas necessidades pessoais e a manutenção de um lugar social. ${ }^{7}$

Com o envelhecimento populacional global, surgem novas ideologias em torno do envelhecer. Fala-se no envelhecimento "ativo", quando, de fato, é melhor pensar num envelhecimento "digno".

\section{A DEMÊNCIA E O MAL DE ALZHEIMER}

A demência é uma síndrome caracterizada pelo declínio de várias habilidades intelectuais, transtorno do comportamento e restrições funcionais. Sua prevalência cresce exponencialmente de $2 \%$ entre pessoas com 65 anos de idade para 20 a $40 \%$ entre aquelas com 80 anos ou mais. Assim sendo, em razão do envelhecimento populacional mundial, estima-se que o número de idosos com demência crescerá consideravelmente durante os próximos anos. ${ }^{8}$

De acordo com a American Psychiatric Association: Diagnostic and Statistical Manual of Mental Disorders: DSM-IV-TR e com a Organização Mundial de Saúde (da CID-10) para o diagnóstico de demência (quadro 20.1), o indivíduo deve ser acometido pela deterioração da memória e das suas funções corticais superiores. É preciso que a pessoa tenha um comprometimento suficientemente grave de 6 JACOB FILHO, Wilson; CHIBA, Toshio. Atendimento Multidisciplinar. In: CARVALHO FILHO, Eurico Thomaz; PAPALÉO NETTO, Matheus (Org.). Geriatria: fundamentos, clínica e terapêutica. Org.: São Paulo: Atheneu, 2000, p. 400.

7 BUSSE, Ewald W. O mito, história e ciência do envelhecimento. 1992, p. 15.

8 ALMEIDA, Osvaldo Pereira de. Demência. In: BOTEGA, Neury José (Org.). Prática Psiquiátrica no hospital geral: interconsulta e emergência. 3. ed. Porto Alegre: Artmed, 2012, p. 280. 
suas habilidades intelectuais, ao ponto de restar prejudicada a sua capacidade funcional. ${ }^{9}$

A demência engloba várias patologias, tendo causas que podem ser divididas em degenerativas, vasculares, metabólicas, tóxicas, inflamatórias/transmissíveis, neoplásicas e mecânicas. Suas quatro causas mais comuns são: o Alzheimer, a demência dos córpulos de Lewy, a demência frontotemporal e a demência vascular. Os fatores causais do Alzheimer ainda não foram compreendidos. Afirma-se que possa ser uma decorrência da conjugação de fatores de risco genéticos e não genéticos. ${ }^{10}$

A doença de Alzheimer é um transtorno neurodegenerativo lento. Os por ela acometidos perdem sua produtividade socioeconômica e o fardo familiar é profundo. Surgem dificuldades de aprendizado. Progressivamente, são atingidas a habilidade matemática, a linguagem, a práxis, a percepção sensorial e as habilidades da visão espacial. São sintomas: a amnésia, a afasia, a agnosia e a apraxia. São afetadas as funções intelectuais. ${ }^{11}$

O diagnóstico precoce do Alzheimer continua a ser um desafio. Um impasse contemporâneo é diferenciar as alterações cognitivas próprias do envelhecimento normal das manifestações das fases iniciais dos transtornos demenciais, particularmente do Alzheimer. Os diagnósticos são imprecisos. ${ }^{12}$

O manejo das alterações comportamentais se dá por meio de estratégias farmacológicas, psicológicas e sociais, gerando gastos. Na maioria dos casos, as intervenções restringem-se ao uso de medicamentos. Pessoas com sintomas psiquiátricos totalmente distintos são tratadas como se fossem um grupo homogêneo de "pacientes com transtorno de comportamento". Tratamentos

9 ALMEIDA, Osvaldo Pereira de. Demência. 2012, p. 280.

10 GELLER, Lisa N.; REICHEL, William. A doença de Alzheimer: aspectos biológicos. In: GALLO, Joseph J.; BUSBY-WHITEHEAD, Jan; RABINS, Peter V.; SILLMAN, Rebecca A.; MURPHY, John B (Org.). Assistência ao idoso: aspectos clínicos do envelhecimento. Tradução de Carlos Alberto Gomes da Silva Junior... [et al.]. Rio de Janeiro: Guanabara Koogan S.A., 2001, p. 181.

11 ALMEIDA, Osvaldo Pereira de. Demência. 2012, p. 284.

12 BOURGEOIS, James A.; SEAMAN, Jeffrey S.; SERVIS, Mark E. Delirium: transtornos amnésticos e outros transtornos cognitivos. In: HALES, Robert H.; YUDOFSKY, Stuart C.; GABBARD, Glen O (Org.). Tratado de psiquiatria clínica. Tradução de: André Campos Gross... [et al.]. 5a ed. Porto Alegre: Artmed, 2012, p. 346. 
experimentais vêm sendo aplicados aos pacientes com demência. Os resultados iniciais são desapontadores. ${ }^{13}$

A última declaração da Organização Mundial de Saúde (OMS) em matéria de Alzheimer, em conjunto com a Associação Internacional da Doença de Alzheimer, datada de 2012, considerou a demência como uma crise de saúde pública, prioridade mundial. O documento intitulado: "Demência: uma prioridade de saúde pública" apresentou dados dos principais estudos realizados, destacando as melhores práticas a serem desenvolvidas na luta contra a doença, além de estatísticas de diversos países. Estimou-se que, a cada ano, surjam 7,7 milhões de casos de demência. Sublinhou-se que o total de pessoas atingidas deverá quase que dobrar a cada 20 anos, podendo passar de 65,7 milhões em 2030 a 115,4 milhões em 2050.14

\section{POLÍTICAS PÚBLICAS DE SAÚDE PARA IDOSOS: UMA ABORDAGEM INTERNACIONAL E COMPARADA}

A expectativa de vida aumentou em decorrência dos avanços científicos e tecnológicos, da melhora das condições socioeconômicas, entre outros fatores. O envelhecimento populacional surgiu como fenômeno mundial, que ocorreu de forma lenta e gradual entre os países desenvolvidos e hoje atinge rápida e intensamente os países em desenvolvimento. A garantia do envelhecimento "digno" se tornou um desafio para as políticas públicas. ${ }^{15}$

A primeira assembleia internacional sobre o envelhecimento ocorreu em 1982. Dela, adveio um plano global de ação composto de recomendações voltadas para sete áreas especialmente: saúde e nutrição; proteção ao consumidor idoso; moradia e meio ambiente; família; bem-estar social; previdência social; trabalho e educação. As recomendações adotadas para os estados membros signatários (dentre os quais estava o Brasil) não foram, contudo, acompanhadas de uma 13 ALMEIDA, Osvaldo Pereira de. Demência, 2012, p. 291.

14 O relatório "Dementia: a public health priority" está disponível para download no site da Alzheimer's Disease International.

15 BARBOZA, Heloisa Helena. O princípio do melhor interesse do idoso. In: PEREIRA, Tânia da Silva; OLIVEIRA, Guilherme de (Org.) O cuidado como valor jurídico. Rio de Janeiro: Forense, 2008, p. 57. 
previsão de recursos respectiva. ${ }^{16}$

Notava-se a importância da medicalização do idoso, que deveria ser inserido no mercado de trabalho, alcançando meios físicos e financeiros para a sua autonomia. Era preciso reconhecê-lo como ator social, dotado de necessidades e especificidades a serem respeitadas por somarem valor à economia e representarem um novo nicho de mercado. ${ }^{17}$

Surgia a ideologia do envelhecimento "ativo", com o discurso da inclusão do idoso na vida socioeconômica. A imagem do idoso aposentado inserido no mercado de trabalho aparecia como algo natural e desejável, além de relevante para a produtividade. Não se levava em conta que, muitas vezes, o indivíduo já tinha em seu histórico de vida uma inserção precoce no mundo do trabalho, tendo sido explorado e expropriado de seus direitos. ${ }^{18}$

A maior preocupação era com os países desenvolvidos, eis que nestes o envelhecimento populacional já ocorria há tempos, como resultado do sucesso das políticas do Welfare State nos anos 50 a 70. Isto, no entanto, não significa dizer que também os países em desenvolvimento não estivessem atentos à questão, eis que paulatinamente incorporavam em suas agendas a atenção a este fenômeno social. Na América Latina, alguns países chegaram a alterar suas constituições, elaborando leis favoráveis à pessoa idosa. Servem de exemplo os casos do Uruguai (1967), Paraguai (1992), Argentina (1994), Venezuela (1999), Equador (2008) e Bolívia (2009). ${ }^{19}$

Na Constituição da República do Uruguai, há apenas uma menção aos direitos dos idosos relativa à seguridade social (art. 67). Contudo, eles são plenamente garantidos por meio da Lei de Promoção Integral aos Idosos, de n 17.996. O art. $2^{\circ}$ desta lei declara como direito dos idosos: a integração ativa na família

16 CAMARANO, Ana Amélia; PASINATO, Maria Teresa. O envelhecimento populacional na agenda das políticas públicas. In: CAMARANO, Ana Amélia (Org.). Os novos idosos brasileiros: muito além dos 60? Rio de Janeiro: Ipea, 2004, p. 255.

17 CAMARANO, Ana Amélia; PASINATO, Maria Teresa. O envelhecimento populacional na agenda das políticas públicas, 2004, p. 255.

18 DANTAS E SILVA, Ferlice; SOUZA, Ana Lúcia de. Diretrizes internacionais e políticas para idosos no Brasil: a ideologia do envelhecimento ativo. Revista de Políticas Públicas. São Luís, v.14, n.1, p. 85-94, jan./jun.2010, p. 90.

19 Para facilitar o acesso aos textos constitucionais eleitos pelos autores na pesquisa de direito comparado, recomenda-se o uso do banco de dados da Georgetown University. 
e na comunidade e o desfrute de um tratamento decente, sem qualquer tipo de discriminação, em todos os aspectos de sua vida; uma velhice digna na qual prevaleça o seu bem-estar físico, psicológico e socioeconômico; os cuidados médicos e de saúde abrangente e coordenada, incluindo dental; o acesso à educação, à moradia adequada, à alimentação e ao abrigo suficientes; o acesso ao lazer, aos transportes e às comunicações em todo o país; a segurança de sua integridade médica e intelectual em um contexto de justiça e equidade. ${ }^{20}$

A Constituição da República do Paraguai apresenta apenas um dispositivo sobre a terceira idade (art. 57) que determina o direito à proteção integral. A família, a sociedade e as autoridades públicas devem promover o seu bem-estar por meio de serviços sociais que atendam às suas necessidades. O Paraguai também possui uma lei que regulamenta a pensão para idosos em situação de pobreza, a Lei $n^{\circ} 3728 / 2009 .{ }^{21}$

A Constituição da República da Argentina traz um dispositivo sobre o assunto (art. 75, linha 23), que menciona a função do parlamento de legislar e promover medidas de ação positiva em favor dos idosos e outras minorias. Entretanto, há um vasto número de normas, sejam de direito interno ou tratado ratificado pela República da Argentina, garantindo os direitos do idoso. Especificamente, há um dispositivo na Constituição da Cidade Autônoma de Buenos Aires (art. 41) determinando que a cidade lhe assegura igualdade de oportunidades e de tratamento, bem como o pleno gozo dos seus direitos. A respeito da seguridade social, há o art. 14 da constituição, salvaguardando que o Estado deverá conceder os benefícios da seguridade social, em caráter integral e inalienável. É previsto um seguro social obrigatório, podendo ser sobrepostas contribuições, aposentadorias e pensões. ${ }^{22}$

A Constituição da República Bolivariana da Venezuela é mais exaustiva quanto ao tema, cabendo dela mencionar um artigo (art. 80). O dispositivo prevê que o Estado deve assegurar aos idosos o pleno exercício de seus direitos e garantias.

20 URUGUAI. Constituição da República. Disponível em: http://pdba.georgetown.edu/ Constitutions/Uruguay/uruguay04.html Acesso em 05 mai. 2014.

21 PARAGUAI. Constituição da República. Disponível em: http://pdba.georgetown.edu/ Constitutions/Paraguay/para1992.html Acesso em 05 mai. 2014.

22 ARGEnTINA. Constituição da Argentina. Disponível em: http://pdba.georgetown.edu/ Constitutions/Argentina/argen94.html Acesso em: 05.05.2014. 
Estado, família e sociedade são obrigados a respeitar a dignidade humana, a autonomia e garantir-lhes cuidados integrais e benefícios de segurança social, a fim de melhorar e assegurar a sua qualidade de vida. Há ainda uma Lei Orgânica de Seguridade Social, promulgada por determinação do art. 86 da constituição. Nessa lei, dispõe o capítulo II sobre o regime de prestação de serviços sociais aos idosos e a outras categorias. O seu art. 59 dispõe que estes serviços compreenderão determinados benefícios, programas e serviços, por ele elencados. Chame-se a atenção para o funcionamento do chamado "combo para vejez" (combo para a velhice) venezuelano, composto por salário mínimo, alimentação e medicamentos. ${ }^{23}$

A Constituição da República do Equador dedica três artigos à terceira idade. O art. 36 estatui a atenção prioritária e especializada nos setores público e privado, além de proteção contra a violência. Serão considerados idosos os que tenham atingido 65 anos. $\mathrm{O}$ art. 37 traz um rol de direitos, entre os quais o do atendimento gratuito e especializado de saúde e o de acesso a medicamentos. 0 art. 38 estabelece que compete ao Estado estabelecer políticas e programas de cuidados para os idosos, considerando as especificidades entre as zonas urbanas e rurais, as desigualdades de gênero, etnia, cultura e suas próprias diferenças. Deverá promover o maior grau possível de autonomia pessoal do idoso, garantida a sua participação nessas políticas. $\mathrm{Na} 25^{\mathrm{a}}$ disposição transitória, estão previstos a revisão anual da aposentadoria e o objetivo de alcançar o salário digno. ${ }^{24}$

Da Constituição da República Boliviana, merecem referência três dispositivos. $\mathrm{O}$ art. 67 preconiza que todos têm direito a uma velhice digna. Além disso, o Estado proverá uma renda vitalícia para os idosos, de acordo com o sistema de segurança social, com previsão em lei. O art. 68 traz a previsão de políticas públicas a serem desenvolvidas pelo Estado para a proteção das pessoas idosas, de acordo com suas capacidades e possibilidades. São passíveis de sanção todas as formas de abuso, negligência, violência e discriminação contra idosos. $O$ art. 69 estabelece que os servidores da pátria são merecedores da gratidão e do

23 VENEZUELA. Constituição da República Bolivariana da Venezuela. Disponível em: http://pdba.georgetown.edu/Constitutions/Venezuela/vigente.html Acesso em: 05.05.2014.

24 EQUADOR. Constituição da República do Equador. Disponível em: http://pdba.georgetown.edu/Constitutions/Ecuador/ecuador08.html Acesso em: 05 mai. 2014. 
respeito de instituições públicas e privadas, bem como do público em geral, sendo considerados heróis e defensores da Bolívia, de modo que farão jus à pensão estatal vitalícia. Sobre a seguridade social, vale citar ainda o art. 45, III, que garante a atenção aos idosos, aos acometidos por enfermidades e epidemias, incapazes e suas necessidades especiais, entre outros. ${ }^{25}$

Na década de 90, os idosos começaram a ser identificados como um segmento populacional ativo. Em 1991, foi realizada uma assembleia geral adotando o princípio das Nações Unidas em favor das pessoas idosas, elencando direitos relativos à independência, à participação, ao cuidado, à autorrealização e à dignidade. Em 1992, houve uma conferência internacional sobre o envelhecer, acolhendo a proclamação do envelhecimento e declarando 1999 o ano internacional do idoso. Em 1995, foi elaborado o Documento 50/114 da ONU, focado em 4 parâmetros, sendo eles: a situação dos idosos, o desenvolvimento individual continuado, as relações multigeracionais e a inter-relação entre envelhecimento e desenvolvimento social. ${ }^{26}$

A segunda assembleia mundial sobre o envelhecimento ocorreu em 2002. Destacou-se que, embora a Europa e a América do Norte lidassem com a questão do envelhecimento há décadas, era chegada a hora de se atentar para os países em desenvolvimento, eis que estes passariam a enfrentar um considerável aumento da população idosa, com possível prejuízo para o desenvolvimento da economia mundial. Foi previsto que, na Ásia e na América Latina, os idosos teriam um crescimento de $8 \%$ para 15\%, entre 1998 e 2025. Em 2050, o percentual poderia chegar a 19\%. O número de crianças cairia de $33 \%$ para $22 \%$, de modo que não tardaria para que o número de idosos e jovens viesse a se igualar mundialmente. ${ }^{27}$

Foi elaborado um plano de ação internacional para o envelhecimento no século XXI, embasado em três princípios: participação social ativa do idoso, desenvolvimento e luta contra a pobreza; estímulo da saúde e bem-estar na

25 BOLÍVIA. Constituição da República Boliviana. Disponível em: http://pdba.georgetown.edu/Constitutions/Bolivia/bolivia09.html. Acesso em: 05 mai. 2014.

26 CAMARANO, Ana Amélia; PASINATO, Maria Teresa. O envelhecimento populacional na agenda das políticas públicas, 2004, p. 257.

27 DANTAS E SILVA, Ferlice; SOUZA, Ana Lúcia de. Diretrizes internacionais e políticas para idosos no Brasil: a ideologia do envelhecimento ativo, 2010, p. 88. 
terceira idade; criação de condições favoráveis ao envelhecimento. Estratégias sugeridas e documentos elaborados foram vagos, desconsiderando as diferenças regionais e sem a previsão dos recursos. ${ }^{28}$

Percebido o alto grau de generalização deste plano, os órgãos regionais das Nações Unidas estabeleceram estratégias para seu funcionamento nas respectivas regiões, consideradas suas especificidades e as dos idosos. Redigiram-se cinco documentos. O documento da Europa norteou-se na imprescindibilidade de assegurar a completa integração e a participação social dos idosos. O documento da América Latina focouse nas necessidades básicas para assegurar a dignidade da pessoa idosa: acesso à renda, à cobertura integral dos serviços de saúde, à educação e à moradia. 0 documento relativo à região da Ásia e do Pacífico foi destinado ao acesso das novas tecnologias, como meio de manter a autonomia e a independência dos idosos, além de fazer referência a um planejamento urbano amigável ao idoso e à importância de elaborar mecanismos de apoio para o cuidador. ${ }^{29}$

O Departamento de Assuntos Sociais e Econômicos das Nações Unidas está à frente de avaliações e revisões do plano de 2002. Enquanto isso, outras iniciativas internacionais podem ser citadas. Dentre elas, por exemplo, ainda em 2002, foi realizada a Conferência Ministerial da UNECE (Comissão Econômica das Nações Unidas para a Europa) sobre o envelhecimento. Em 2007, houve nova Conferência Ministerial da UNECE sobre o envelhecimento. Em 2008, a UNECE criou um grupo de trabalho sobre o envelhecer. Em 2012, ocorreu outra Conferência Ministerial da UNECE sobre a velhice. $O$ ano de 2012 foi o ano europeu do envelhecimento ativo e da solidariedade entre as gerações. ${ }^{30}$

Países da América Latina e Caribe, para o cumprimento das recomendações do plano internacional sobre o envelhecimento de 2002, se comprometeram a implantar políticas públicas e ações. Logo, em 2003, realizou-se, em Santiago do Chile, a primeira conferência regional internacional governamental sobre o

28 CAMARANO, Ana Amélia; PASINATO, Maria Teresa. O envelhecimento populacional na agenda das políticas públicas, 2004, p. 261.

29 CAMARANO, Ana Amélia; PASINATO, Maria Teresa. O envelhecimento populacional na agenda das políticas públicas, 2004, p. 262.

30 Os dados destacados foram coletados no site do GEP PORTUGAL (Gabinete de Estratégia e Planejamento de Portugal). 
envelhecimento na América Latina e no Caribe, sendo aprovada a estratégia regional de implementação na América Latina e no Caribe do plano internacional de 2002. Seguiram-se diversos eventos com o foco nas questões do envelhecer, considerando-se as especificidades culturais, sociais e econômicas de cada país. Em 2007, a Comissão Econômica para a América Latina e o Caribe (CEPAL), organizou, em parceria com o Brasil, a segunda conferência regional intergovernamental sobre o envelhecimento na América Latina e no Caribe, a fim de identificar as prioridades futuras de aplicação da estratégia regional de implementação para a América Latina e o Caribe do Plano Internacional de 2002. Foi elaborada a Declaração de Brasília, em que se assumiram compromissos de promover e prestar serviços sociais e de saúde básica, facilitando o acesso a eles, considerando as necessidades específicas dos idosos. Em 2012, foi realizada a terceira conferência intergovernamental sobre envelhecimento na América Latina e no Caribe, organizada pela CEPAL e pelo governo da Costa Rica. Nessa ocasião, foi redigida a Carta de São José sobre os direitos dos idosos da América Latina e do Caribe. Em 2013, se deu a primeira reunião para dar continuidade à Carta de São José, quando se privilegiou a discussão sobre os mecanismos de cumprimento do estabelecido na terceira conferência regional intergovernamental sobre o envelhecimento na América Latina e no Caribe. ${ }^{31}$

Cabe mencionar o Plano de ação sobre a saúde das pessoas idosas, incluindo o envelhecimento ativo e saudável (Organização Pan-Americana da Saúde, Washington, 2009). Nele, abordam-se as necessidades de saúde da população, que está envelhecendo rapidamente na América Latina e no Caribe. Incentiva-se que os países membros da OPAS e os organismos de cooperação internacional priorizem as políticas públicas atinentes à saúde dos idosos. No Plano de Ação, estão definidas as prioridades de 2009-2018. ${ }^{32}$

É chegada a hora de analisar a questão do envelhecimento nas políticas públicas brasileiras. Começa-se por destacar que, como signatário do primeiro plano

31 A Declaração de Brasília está exposta no site do Observatório Nacional do Idoso Fiocruz. A Carta de São José sobre os direitos dos idosos da América Latina e do Caribe está disponível no sítio da Secretaria de Direitos Humanos.

32 O Plano de Ação da Organização Pan-Americana de Saúde 2009-2018 está disponível para acesso no site: SISAP IDOSO (Sistema de Indicadores de Saúde e Acompanhamento de Políticas do Idoso). 
internacional sobre o envelhecer, é possível afirmar que a questão da inserção do envelhecimento populacional na agenda das políticas públicas brasileiras não é nova. Ao revés, pode ser percebida antes mesmo da Constituição de $1988 .{ }^{33}$

Esta constituição trouxe considerável avanço para a proteção dos idosos brasileiros. Foi inserido um conceito de seguridade social segundo o qual a proteção social não está mais vinculada ao contexto estritamente socialtrabalhista, passando a ser uma expressão da cidadania. Garantiu-se o acesso à saúde e à educação para toda a população e, ainda, a assistência social para os necessitados. No título relativo à Ordem Social, tratou da família, da criança, do adolescente e do idoso. Assegurou aos idosos a participação social, garantindo a respectiva dignidade, bem-estar e direito à vida, que devem ser protegidos pela família, sociedade e Estado. Estabeleceu que os programas de cuidado do idoso serão prioritariamente desenvolvidos em suas residências. Assegurou a gratuidade dos transportes coletivos urbanos para os maiores de 65 anos, em todo o território nacional (art. 230). Vedou a possibilidade de estabelecimento de diferenças salariais, exercício de funções e critérios de admissão pautados em razão de idade. Incidiu, no entanto, em erro quando manteve a aposentadoria compulsória nos regimes de previdência dos servidores públicos e privados, trazendo aí uma discriminação.

Critica-se a Constituição, por ser explícita quanto à prioridade absoluta das crianças e dos adolescentes, nada dizendo quanto à primazia dos idosos. Entretanto, existem doutrinadores que afirmam que a pessoa humana surgiu como um dos fundamentos do Estado Democrático de Direito, tendo sido acolhida uma cláusula geral de tutela da pessoa humana, da qual se pode extrair a consagração do princípio do melhor interesse do idoso. ${ }^{34}$

A partir de 90, diversos dispositivos constitucionais relativos às políticas setoriais de proteção dos idosos foram regulamentados. Políticas e programas nacionais de saúde foram adotados. Alguns destinados especificamente aos idosos, outros direcionados a toda a população, mas que igualmente a eles interessaram. Tais

33 CAMARANO, Ana Amélia; PASINATO, Maria Teresa. o envelhecimento populacional na agenda das políticas públicas, 2004, p. 263.

34 BARBOZA, Heloisa Helena. O princípio do melhor interesse do idoso, 2008, p. 57. 
políticas dialogam entre si, abrangendo questões como: a renda (aí inseridas: a previdência e a assistência social); a saúde; os cuidados de longa permanência e integração social. Foi produzida extensa legislação. ${ }^{35}$

O problema é complexo e a verdade é que a eficácia social efetiva da legislação não aconteceu. Sob o rótulo de idosos, estão indivíduos em torno de 60 anos ou pouco mais, bem como outros extremamente mais velhos, com 90, 100 ou mais. Surge a necessidade se lidar com o "envelhecimento do envelhecimento". Tratase de um grupo bastante heterogêneo e que exige a adoção de políticas públicas de saúde atendendo suas necessidades especiais. As diretrizes desconsideram essa heterogeneidade entre os idosos.

Condições econômicas, culturais e regionais, acesso à rede de serviços básicos, tais como saúde, educação, saneamento básico e lazer, constituem elementos capazes de influenciar na qualidade de vida de um indivíduo, seja ele idoso ou não. Não se pode pretender identificar os idosos como um segmento homogêneo com necessidades idênticas, tendo, pois, peculiaridades próprias a serem consideradas nas políticas públicas respectivas. ${ }^{36}$

Uma mostra disso advém da análise do padrão da chamada morbimortalidade (o impacto das doenças e das mortes nos idosos), que neles é distinto do restante da população. O idoso demanda uma política especial de saúde e com atenção voltada para as enfermidades crônicas (como o Alzheimer), que, comumente, o acometem. Estas últimas exigem um número considerável de consultas médicas, internações, exames e medicamentos, entre outras medidas. Atender aos interesses dos idosos com doenças crônico-degenerativas ainda é um grande desafio em matéria de políticas públicas.

É preciso fomentar a organização da saúde do idoso, em especial daquele com demência (sobretudo o acometido pelo Alzheimer), o que resultará na redução dos custos. As políticas públicas de atenção aos idosos devem se pautar no dever de solidariedade, que tem previsão constitucional (art. $3^{\circ}$, I). Embora se fale em 35 Os interessados no exame da vasta legislação produzida devem conferir a relação das leis, políticas e portarias trazida pelo site: SISAP IDOSO (Sistema de Indicadores de Saúde e Acompanhamento de Políticas do Idoso).

36 DANTAS E SILVA, Ferlice; SOUZA, Ana Lúcia de. Diretrizes internacionais e políticas para idosos no Brasil: a ideologia do envelhecimento ativo, 2010, p. 85. 
políticas públicas de saúde para o idoso, sua abordagem deverá ser intersetorial e as melhorias desde a infância. ${ }^{37}$

\section{POLÍTICAS PÚBLICAS DE SAÚDE PARA IDOSOS COM ALZHEIMER: UM EXERCÍCIO DE COMPLEXIDADE E ESPECIFICIDADE}

Em face da Declaração da OMS (2012), no sentido da necessidade de se declarar a demência uma prioridade mundial de saúde pública, e dos dados estatísticos apresentados acerca da numerosa quantidade de pessoas, ao redor do mundo, afetadas por demências, passa a ser de interesse inequívoco a realização de estudos sobre políticas públicas adotadas em saúde para os idosos, que são a camada mais comumente por elas atingidas, especialmente pelo Alzheimer. Tornase oportuno examinar quais as respostas dadas mundialmente ao verdadeiro chamado ao planeta feito pela OMS.

Começa-se abordando a iniciativa europeia em matéria de Alzheimer e outras demências. Nisso, merece menção: o relatório A7-0366/2010 da Comissão do Ambiente, da Saúde Pública e da Segurança Alimentar, apresentado pelo Parlamento Europeu, em 09.12.2010, que, após debates e votação, resultou na aprovação do texto P7-TA (2011)0016, que compreende a resolução do Parlamento Europeu, de 19.01.2011, sobre a iniciativa europeia relativamente a estas doenças. O relatório trouxe uma proposta de resolução que se pautava: na necessidade de adoção de medidas de luta contra as doenças neurodegenerativas associadas à idade, em especial o Alzheimer, reconhecidas em recomendação do Conselho Europeu; nas conclusões do projeto EuroCoDe da organização Alzheimer Europe (colaboração europeia sobre demência) (2006-2008); no relatório mundial de 2010 sobre o Alzheimer; no objetivo estratégico da União Europeia de promover a saúde numa Europa que envelhecia e se encontrava em face da necessidade de intensificar a investigação no interesse dos cuidados paliativos e de uma melhor compreensão de tais patologias. Segundo o relatório (2010), as estimativas eram de que, em todo o mundo, 35,6 milhões de pessoas sofriam de alguma forma de

37 MORAES, Maria Celina Bodin de. O princípio da solidariedade. In: PEIXINHO, Manoel Messias; GUERRA, Isabella Franco; NASCIMENTO FILHO, Firly (Org.). Os princípios da Constituição de 1988. Org. Rio de Janeiro: Lumen Juris, 2001, p. 168. 
demência, sendo possível prever que este número deveria praticamente duplicar a cada 20 anos, podendo chegar a 65,7 milhões em 2030, de acordo com relatório de 2010 da organização Alzheimer's Disease International, estando o número de doentes de Alzheimer subavaliado, em razão de dificuldades na realização de um diagnóstico precoce. Naquela ocasião, o número de europeus com demência ficava em torno de 9,9 milhões, sendo o Alzheimer responsável pela vasta maioria dos casos. $^{38}$

Cumpre citar também que a Alzheimer Europe e as suas organizações membros apelaram à União Europeia, à Organização Mundial de Saúde, ao Conselho da Europa e aos governos nacionais para declararem o Alzheimer um problema maior de saúde pública e desenvolverem programas internacionais, nacionais e europeus específicos para esta forma de demência como prioridades políticas. Foi aprovada a Declaração de Paris (2006). ${ }^{39}$

Dados fornecidos pela Alzheimer Europe, em 24.02.2014, estimam a existência hoje de 8,7 milhões de pessoas com demência nos Estados membros da União Europeia e 0,5 milhões de pessoas com demência na Suíça, Noruega, Islândia, Jersey e Turquia. Não se pode ter dúvida de que, com o atual aumento na expectativa de vida da população da Europa, o número de pessoas afetadas por doenças relacionadas à idade, como o Alzheimer, irá crescer dramaticamente nos próximos anos. ${ }^{40}$

A partir de informações da Alzheimer Europe, vê-se que nem todos os países membros da União Europeia tem um Plano Nacional de luta contra o Alzheimer, porém muitos já adotaram medidas relativas à questão. É interessante, pois, fazer um levantamento de alguns países que tomaram essa iniciativa, não só na Europa.

38 O relatório A7-0366/2010 apresentado pelo Parlamento Europeu, bem como o texto P7TA (2011)0016 estão disponíveis para visualização no Sítio Web do Parlamento Europeu. Verifique-se em: http://www.europarl.europa.eu. Acesso em: 06.05.2014.

39 O site da Alzheimer Europe traz estudos comparativos dos estágios de evolução dos Programas de Luta contra o Alzheimer nos 28 Estados-Membros que compõem hoje a União Europeia. Traz também a Declaração de Paris. Disponível em: http://www.alzheimer-europe. org/. Acesso em: 06.05.2014.

40 Leia-se sobre o assunto, as informações do Site Alzheimer Europe. Disponível em: http:// www.alzheimer-europe.org/. Acesso em: 05.05.2014. 
Na França, o Alzheimer é a forma mais comum de demência, representando cerca de 60 a 70\% dos casos de sua incidência. Diante disso, são empreendidos esforços para o desenvolvimento de medidas para dar cabo das demências. Existem planos nacionais quinquenais de luta contra o Alzheimer, tendo o penúltimo se desenvolvido no período de 2008 a 2012, estando em curso o plano 2013-2018. ${ }^{41}$

A Alzheimer Portugal defende a necessidade de um Plano Nacional para as demências. Em 2013, quando o número de pessoas acometidas por demência no país ultrapassava 153.000, dos quais mais de 90.000 com Alzheimer, o Presidente do Conselho Nacional de Saúde Mental, António Leuschner, afirmou que, em 2014, este plano se tornaria uma realidade. ${ }^{42}$

Os EUA admitiram a inafastabilidade de uma estratégia nacional de luta contra o Alzheimer, que é a sexta causa de morte entre os americanos. Em 2010, o Congresso aprovou o Projeto de Lei Nacional Alzheimer (PL 111-375), instituindo o Departamento de Saúde e Serviços Humanos para desenvolver um plano específico para a doença. Atualmente, existe um Plano Nacional de Alzheimer atualizado anualmente. Em 2014, os custos de atenção foram estimados em 172 milhões de dólares, com a previsão de um gasto superior a 1 trilhão de dólares em 2050. Neste ano, foi introduzido o Accountability Act de Alzheimer, visando garantir que o Congresso estará equipado com informações para definir as prioridades de financiamento e alcançar a meta do Plano Nacional de Doença de Alzheimer, voltado para o propósito de que a prevenção e o tratamento da doença se deem de forma eficaz até $2025 .{ }^{43}$

No Canadá, em 2014, seriam 747.000 canadenses afetados pelo Alzheimer ou doenças aparentadas. As estimativas são de que, se nada for feito a este respeito, tais patologias vitimarão 1,4 milhão de canadenses em 2031, chegando os custos econômicos a 293 milhões de dólares em 2040. Segundo declaração 41 Caso haja interesse na análise do Plano Nacional quinquenal de luta contra o Alzheimer adotado na França (2008-2012), o documento pode ser encontrado no site: sante.gouv.fr do Ministère des Affaires Sociales de la Santé. Está disponível em: http://www.sante.gouv. fr/le-plan-alzheimer-2008-2012,972.html. Acesso em: 07.05.2014.

42 A este respeito, é válido conferir as notícias do site da Alzheimer Portugal. Sugere-se a leitura do sítio: http://www.alz.org/news_and_events_alzheimers_accountability_act.asp. Acesso em: 05.05.2014.

43 Estas notícias estão disponíveis no site da Alzheimer's Association. 
da Société Alzheimer Society, o plano nacional de combate ao Alzheimer e doenças assemelhadas deve fazer parte das prioridades do orçamento federal. A chefe da direção da Société Alzheimer Canadá, Mimi Lowi-Young, demandará ao governo 3 milhões de dólares para a formação de uma parceria canadense contra o Alzheimer e outras doenças neurodegenerativas, reunindo líderes de opinião, governantes e os porta-vozes e setores da saúde, pesquisa, academia e indústria para conseguir implementar um Plano Nacional contra o Alzheimer. ${ }^{44}$

Na Argentina, estima-se que 500.000 pessoas tenham Alzheimer, acreditandose que haverá um aumento exponencial deste número nos próximos anos, sendo o problema entendido como uma questão a ser observada pelos setores de saúde pública. No Chile, em 2012, a Corporação Profissional Alzheimer e outras demências e a Sociedade Neurologia, Neurocirurgia e Psiquiatria iniciaram uma campanha de recolhimento de assinaturas para sensibilizar as autoridades e pedir-lhes o desenvolvimento de um plano de políticas públicas de atenção aos doentes com Alzheimer. Esta é a quarta causa de morte neste país, afetando diretamente 180.000 pessoas. Em notícia da Alzheimer's Internacional, datada de 2013, se teve conhecimento que uma lei peruana deu início a um Plano Nacional de Demência, sendo o Peru o primeiro país da América Latina a adotar uma estratégia deste tipo. ${ }^{45}$

Sobre a realidade dos idosos na América Latina, estudos apontam a presença da desigualdade social em saúde. Tais diferenças estariam associadas à diversidade no estágio e na velocidade da mudança demográfica e aos indicadores socioeconômicos dos respectivos países. ${ }^{46}$

44 Os dados acima foram obtidos no site da Société Alzheimer Society. Leia-se: Dados da Société Alzheimer Society. Disponíveis em: http://www.alzheimer.ca/ /media/Files/national/ Media-releases/asc_release_01152014_pre-budget_f.ashx. Acesso em: 05 mai. 2014.

45 O levantamento de dados e as informações sobre os avanços recentes na luta contra o mal de Alzheimer na América Latina foi realizado a partir de consultas realizadas nos seguintes sítios: Site Corporación Profesional Alzheimer y otras demencias (COPRAD). Disponível em: http://neurologiacognitiva.cl/coprad/plan-nacional/. Acessado em: 05.05.2014; Site Revista Chilena de Salud Publica disponível em: http://pt.scribd.com/doc/144665136/Revista-Chilena-de-Salud-Publica-Vol-17-No-1-2013 acessado em 06.05.2014; Site Revista Argentina Alzheimer y otros trastornos cognitivos disponível em: www.alzheimer.org.ar/ revista15.pdf acessado em 05.05.2014, Notícias Alzheimer's Disease International disponíveis em: http://www.alz.co.uk/news/national-dementia-plan-confirmed-for-peru. Acesso em: 07.05.2014.

46 NORONHA, Kenya Valéria Micaela; ANDRADE, Mônica Viegas. Desigualdade social em saúde entre idosos da América Latina. Disponível em: http://www.abep.nepo.unicamp. 
Diante do contexto sociocultural da América Latina, afirma-se que o fenômeno do envelhecimento populacional assume características distintas daquelas próprias dos países mais desenvolvidos. Nos países latino-americanos, a situação social, política e econômica resulta em perigo para a qualidade do atendimento dos idosos, sendo insuficiente o suporte fornecido. ${ }^{47}$

No Mercosul, a ótica comercial faz com que temas relativos às políticas sociais se desenvolvam lentamente e subordinados à eliminação de barreiras e à circulação de produtos. No entanto, é possível afirmar existirem realizações em diferentes políticas públicas. ${ }^{48}$ Em 2012, países do Mercosul criaram a primeira rede de investigação em biomedicina. O projeto durará três anos e aborda os aspectos biológicos, epidemiológicos e sociológicos de doenças degenerativas da região, dentre as quais está o Alzheimer. ${ }^{49}$

O Brasil é um país que está envelhecendo e necessitando se preparar com políticas públicas de atenção aos idosos. O crescimento populacional é acompanhado pela incidência significativa de casos de enfermidades crônicodegenerativas, como o Alzheimer. Os direitos do idoso aparecem garantidos por leis, porém não na prática. Ainda é precário o suporte dado aos idosos, com problemas de saúde e acometidos de demência.

Em média, 25\% dos idosos presentes em entidades asilares brasileiras são compostos por pessoas acometidas de demência. Necessário adotar estratégias para proteger seus interesses. Nesse particular, há quem difira o idoso dependente do idoso frágil, sendo a situação deste último ainda mais preocupante. O idoso dependente é, neste caso, aquele que possui limitações para atividades básicas da vida diária, o idoso frágil o que não tem forças para reagir a situações de

br/SITE_EVENTOS_ALAP/PDF/ALAP2004_239.PDF. Acesso em: 01 mai. 2014, p.12.

47 BULLA, Leonia Capaverde; TSURUZONO, Eleni Raquel da Silva. Envelhecimento, família e políticas sociais. Revista de Políticas Públicas. São Luís, v.14, n.1, p.103-112, jan./ jun.2010, p. 104.

48 QUEIROZ, Luísa Guimarães; GIOVANELLA, Ligia. Agência regional de saúde no Mercosul: arquitetura e temas. Revista Panamericana de Salud Publica. Washington, v.30, n.2, p. 182-188, agosto/2011, p. 188.

49 Para informações sobre a Rede de Investigação em Biomedicina, os autores sugerem se examine o site da Agência Fiocruz de Notícias. Recomenda-se a leitura no sítio: AGÊNCIA FIOCRUZ DE NOTÍCIAS disponível em: https://www.agencia.fiocruz.br/semin\%C3\%A1rio-fiocruzaviesan-novos-caminhos-para-tratamento-de-alzheimer-parkinson-e-depress\%C3\%A3o Acesso em: 05.05.2014. 
perigo, como as de violência física ou psicológica. ${ }^{50}$

A inclusão da mulher no mercado de trabalho, a redução de tamanho das residências e o ritmo do cotidiano das cidades contribuíram para que não se saiba quem cuidará do idoso. Pensa-se em institucionalizá-lo numa instituição de longa permanência. Com isso, não se afastará a responsabilidade da família, cuja participação é de fundamental importância, ainda mais em se tratando de um idoso dependente (ou frágil). A situação é complexa, havendo grande stress familiar daqueles que cuidam do idoso, o que pode vir a ensejar a união da família para dar cabo do problema ou, ao revés, a desagregação familiar. Muitas vezes, opta-se pelo cuidador não familiar, solução cercada de alto custo. ${ }^{51}$

As instituições de longa permanência, normalmente, não têm estrutura física e operacional especializada para cuidar dos idosos com demência. São desprovidas da licença autorizadora do Ministério da Saúde para a prestação de serviços abalizados. Os cuidados prestados se dão de forma abnegada, com os recursos que possuem, sem auxílio metodológico e recursos humanos da gestão de saúde do Poder Público. Há o fato de que, conforme maior o estado de dependência/ fragilidade do idoso, mais caros os gastos.

A Lei da Reforma Psiquiátrica (Lei n010.216/2011) é desrespeitada, em especial o seu art. $3^{\circ}$, de acordo com o qual é da responsabilidade do Estado o desenvolvimento de uma política de saúde mental, assistência e promoção de ações de saúde aos portadores de transtorno mental, com a devida participação da sociedade e da família, a qual será prestada em estabelecimento de saúde mental, isto é, instituições ou unidades que ofereçam assistência em saúde. A Lei de Política Nacional do Idoso e o Estatuto do Idoso também são desrespeitados, por conseguinte.

A discussão sobre a implantação de políticas públicas para idosos com demência e portadores de Alzheimer, em especial, ainda é residual. Sugere-se que o poder público brasileiro projete e construa centros geriátricos de saúde

50 BULLA, Leonia Capaverde; TSURUZONO, Eleni Raquel da Silva. Envelhecimento, família e políticas sociais, 2010, p. 108.

51 BULLA, Leonia Capaverde; TSURUZONO, Eleni Raquel da Silva. Envelhecimento, família e políticas sociais, 2010, p. 106. 
mental, com dois regimes: o de internato e o de centro-dia, a fim de se dar o tratamento adequado e especializado a essas pessoas, aí incluídas as que estão institucionalizadas e as que ainda possuem vínculos familiares, plenos ou fragilizados. As entidades asilares, efetivamente, precisam melhorar o ambiente dos idosos residentes, propiciando-lhes maior tranquilidade, sendo menor a sobrecarga de trabalho para os funcionários. Argumenta-se que é essencial buscar a maior intersetorialidade entre a assistência social e a saúde. As universidades brasileiras devem investir nos estudos deste segmento de idosos. ${ }^{52}$

Destaca-se a importância de serem destinados mais recursos humanos no trato da questão. Salienta-se a necessidade de empreender esforços na capacitação das equipes de saúde, que deverão passar a considerar aspectos relevantes como a história de vida do idoso em tratamento e o respeito à diferença. Mais espaços de reflexão sobre o problema são pensados. Além disso, como os diagnósticos das doenças neurodegenerativas costumam ser imprecisos e dada a vantagem que decorreria se houvesse um diagnóstico mais precoce da doença, acreditase que é preciso um plano de ação voltado para a questão do diagnóstico. Este deverá considerar fatores como as singularidades do idoso, interpretando suas falas e avaliando a conduta dos familiares, identificando problemas e necessidades específicas. ${ }^{53}$

No Brasil, existem programas e serviços de atendimento ao idoso, porém é fato que, comumente, a demanda ultrapassa a possibilidade de oferta pelo poder público. O funcionamento das distintas modalidades de serviço requer a realização de gastos econômicos consideráveis, sendo imprescindível ainda que haja uma criteriosa avaliação prévia do caso antes da indicação do serviço, além da já citada imprescindibilidade de uma formação de recursos humanos profissionalmente mais preparados. ${ }^{54}$

52 STUCCHI, Cláudio. A falta de políticas públicas para idosos com demência. Disponível em: http://www.previnerconsultoria.com.br/index.php/component/content/article/47-artigosdo-terceiro-setor/119-artigo-a-falta-de-politicas-publicas-para-os-idosos-institucionalizados-que-sofrem-com-demencia.html. Acesso em: 01.05.2014, p. 2.

53 BULLA, Leonia Capaverde; TSURUZONO, Eleni Raquel da Silva. Envelhecimento, família e políticas sociais, 2010, p. 108.

54 BULLA, Leonia Capaverde; TSURUZONO, Eleni Raquel da Silva. Envelhecimento, família e políticas sociais, 2010, p. 110. 
Embora as doenças crônico-degenerativas afetem cada vez mais os idosos brasileiros, ainda não se tem uma resposta social à altura do problema. O que se pode notar são iniciativas isoladas. Em meio a estas, está o Programa de Assistência aos Portadores da Doença de Alzheimer (Portaria MS/GM n 703, de 16 de abril de 2002), instituído no âmbito do Sistema Único de Saúde, devendo ser desenvolvido de forma articulada pelo Ministério da Saúde e pelas Secretarias de Saúde dos Estados, Distrito Federal e Municípios em cooperação com as redes estaduais de assistência e centros de referência em assistência à saúde do idoso. ${ }^{55}$

A Portaria MS/SAS no 249/2002 aprovou as normas para cadastramento dos Centros de Referência em Assistência à Saúde do Idoso, determinando que o tratamento do Alzheimer devesse ser realizado conforme o Protocolo Clínico e Diretrizes Terapêuticas publicados pela Secretaria de Assistência à Saúde. Este protocolo só veio a ser regulamentado em 2010, pela Portaria MS/SAS n 491. Nele, consta o conceito geral de Alzheimer, critérios de diagnóstico, de inclusão e de exclusão, tratamento e mecanismos de regulação, controle e avaliação. ${ }^{56}$

\section{CONSIDERAÇÕES FINAIS}

Conclui-se que as políticas públicas não se originaram da preocupação com o ser humano, mas com o envelhecimento populacional o e seu impacto na economia, previdência social e sistema de saúde. Por esse motivo, a solução encontrada foi a de recolocar o idoso no mercado de trabalho, sob a bandeira do que se convencionou chamar de envelhecimento "ativo", revestida da falácia de que seria uma "terapia", em detrimento de uma proposta focada em um envelhecer "saudável" e "digno".

As atuais políticas internacionais e nacionais de proteção social ao idoso se encaixam no pragmatismo individualista, ignorando o princípio da solidariedade. São políticas de exploração do segmento idoso. Com elas, o que se visa, em primeiro lugar, é a defesa do capital e, apenas, num segundo plano, a tutela dos 55 A Portaria MS/GM no 703/2002 está disponível em: http://www.saudeidoso.icict.fiocruz.br/ index.php?pag=polit. Acesso em: 06.05.2014.

56 A Portaria MS/SAS no 491/2010 está disponível em: http://www.saudeidoso.icict. fiocruz. br/index.php?pag=polit. Acesso em: 06.05.2014. 
interesses humanos. A atenção está voltada para o fato de o envelhecimento populacional extremado desviar recursos financeiros e humanos para um setor que não oferece o retorno economicamente almejado.

A produtividade econômica e social dessas pessoas vítimas do "envelhecimento do envelhecimento" se vê seriamente comprometida pela deterioração da saúde. Nesse momento, elas se tornam desinteressantes e até onerosas para o Estado, razão pela qual se atribui a demora na adoção de medidas na área de saúde para a terceira idade ao descaso político eleitoral, por parte da administração pública e da representação legislativa.

O que se verifica é um descompasso entre reconhecimento obtido no plano normativo internacional sobre o envelhecimento do idoso como ator social, com as necessidades e as especificidades próprias e a praxe da Administração Pública dos Estados. Estes são condicionados por interesses pragmáticos e imediatistas, que otimizam a alocação de recursos, fundamentalmente, para a promoção de interesses econômicos privados.

Nesse contexto, são extremamente preocupantes os dados que apontam para o flagrante crescimento do número de casos de doenças crônicas, como o Alzheimer na população mundial (aí incluída a brasileira), sem que as organizações internacionais e os governos nacionais estejam preparados para isto. É premente a necessidade da adoção de políticas públicas concretas focadas na eficiência operacional e na dignidade do idoso, com diretrizes próprias para solucionar o problema.

A incidência elevada de casos de Alzheimer entre idosos no Brasil justifica que, a exemplo do que vem ocorrendo em outros países, elabore-se um Plano Brasileiro de Combate ao Alzheimer, adequado às condições sociais, políticas, econômicas e culturais brasileiras. Para tanto, é de fundamental relevância o apoio dos gestores federais, estaduais e municipais; da Associação Brasileira de Alzheimer (ABRAZ) e seus associados; das instituições privadas e públicas; da sociedade brasileira. Este plano teria por objetivos: reunir condições para um diagnóstico mais precoce; otimizar a saúde física, cognitiva e o bem-estar do doente; a proteção e o tratamento de doenças psíquicas concomitantes; a detecção e o tratamento de sintomas psicológicos e comportamentais; a 
prestação de informações e o apoio a longo prazo para aqueles que prestam os cuidados. Suas grandes orientações seriam: o reforço da dimensão ética no apoio aos acometidos pela doença; o desenvolvimento de pesquisas médicas a seu respeito; a simplificação e a melhora do curso da doença para aquele que é por ela afetado e para a sua família, em todas as dimensões possíveis; a melhora das condições para um diagnóstico mais precoce da patologia.

É desejável também que o Mercosul acelere sua cooperação na luta contra este mal e empreenda uma reação regional de combate ao Alzheimer e às demências associadas. Indo além, considerando que o envelhecimento populacional é uma questão atual e global, tendo ficado evidenciado que, com o envelhecer, aumenta e muito a incidência destas doenças, espera-se uma reação mundial efetiva para o problema ainda venha a ocorrer.

\section{REFERÊNCIAS}

AGÊNCIA FIO CRUZ DE NOTÍCIAS. Notícias sobre a rede de investigação em biomedicina constituída pelos países do Mercosul. Disponíveis em: http://www.agencia.fiocruz.br/ pa\%C3\%ADses-do-mercosul-criam-rede-de-investiga\%C3\%A7\%C3\%A3o-em-biomedicina. Acesso em: 05 mai 2014.

ALMEIDA, Osvaldo Pereira de. Demência. In: BOTEGA, Neury José (Org.). Prática psiquiátrica no hospital geral: interconsulta e emergência. 3. ed. Porto Alegre: Artmed, 2012.

ALZHEIMER'S ASSOCIATION. Notícias. Disponíveis em: http://www.alz.org/news_and_events_ alzheimers_accountability_act.asp. Acesso em 05 mai. 2014.

ALZHEIMER'S DISEASE INTERNATIONAL. Dementia: a public health priority. Disponível em: http://www.alz.co.uk/WHO-dementia-report. Acesso em: 05 mai 2014.

Notícias. Disponíveis em: http://www.alz.co.uk/news/national-dementia-planconfirmed-for-peru. Acesso em: 07 mai. 2014.

ALZHEIMER EUROPE. Disponível em: http://www.alzheimer-europe.org/. Acesso em: 05 mai. 2014.

ALZHEIMER PORTUGAL. Notícias. Disponíveis em: http://alzheimerportugal.org/pt/news_ text-77-1-142-plano-nacional-para-as-demencias-em-2014. Acesso em: 05 mai. 2014.

ALZHEIMER Y OTROS TRASTORNOS COGNITIVOS. Disponível em: www.alzheimer.org.ar/ revista15.pdf. Acesso em: 05 mai. 2014. 
ARGENTINA. Constituição da Argentina. Disponível em: http://pdba.georgetown.edu/ Constitutions/Argentina/argen94.html Acesso em: 05.05.2014.

BARBOZA, Heloisa Helena. O princípio do melhor interesse do idoso. In: PEREIRA, Tânia da Silva; OLVEIRA, Guilherme de (Org.). $O$ cuidado como valor jurídico. Org.: Rio de Janeiro: Forense, 2008.

BOURGEOIS, James A.; SEAMAN, Jeffrey S.; SERVIS, Mark E. Delirium: transtornos amnésticos e outros transtornos cognitivos. In: HALES, Robert H.; YUDOFSKY, Stuart C.; GABBARD, Glen O. (Org.). Tratado de psiquiatria clínica. Tradução de André Campos Gros [et al.]. 5. ed. Porto Alegre: Artmed, 2012.

BRASIL. Ministério da Saúde. Portaria MS/GM n 703, de 16 de abril de 2002. Programa de Assistência aos Portadores da Doença de Alzheimer. Disponível em: http://www.saudeidoso. icict.fiocruz.br/index.php?pag=polit. Acesso em: 06 mai. 2014.

BRASIL. Ministério da Saúde. Portaria MS/SAS n 491/2010. Disponível em: http://www. saudeidoso.icict.fiocruz.br/index.php?pag=polit. Acesso em: 06 mai. 2014.

BULLA, Leonia Capaverde; TSURUZONO, Eleni Raquel da Silva. Envelhecimento, família e políticas sociais. Revista de Políticas Públicas. São Luís, v.14, n.1, p.103-112, jan./jun.2010.

BUSSE, Ewald W. O mito, história e ciência do envelhecimento. In: BUSSE, Ewald W.; BLAZER, Dan G (Org.). Psiquiatria geriátrica. Tradução de Maria Cristina Monteiro Goulart. Porto Alegre: Artes Médicas, 1992.

CAMARANO, Ana Amélia; PASINATO, Maria Teresa. O envelhecimento populacional na agenda das políticas públicas. In: CAMARANO, Ana Amélia (Org.). Os novos idosos brasileiros: muito além dos 60? Rio de Janeiro: Ipea, 2004.

CARTA DE SÃO JOSÉ SOBRE OS DIREITOS DOS IDOSOS DA AMÉRICA LATINA E DO CARIBE. Disponível em: http://www.sdh.gov.br/assuntos/pessoa-idosa/legislacao/pdf/carta-de-saojose. Acesso em: 06 mai. 2014.

CORPORACIÓN PROFESIONAL ALZHEIMER Y OTRAS DEMENCIAS (COPRAD). Disponível em: http://neurologiacognitiva.cl/coprad/plan-nacional/. Acesso em: 05 mai. 2014.

DADOS DA SOCIÉTÉ ALZHEIMER SOCIETY. Disponíveis em: http://www.alzheimer.ca/ /media/Files/ national/Media-releases/asc_release_01152014_pre-budget_f.ashx. Acesso em: 05 mai. 2014.

DANTAS E SILVA, Ferlice; SOUZA, Ana Lúcia de. Diretrizes internacionais e políticas para idosos no Brasil: a ideologia do envelhecimento ativo. Revista de Políticas Públicas. São Luís, v.14, n.1, p. 85-94, jan./jun.2010. 
DECLARAÇÃO DE BRASÍLIA. Disponível em: http://www.observatorionacionaldoidoso.fiocruz. br/biblioteca/_informes/11.pdf. Acesso em: 06 mai. 2014.

DECLARAÇÃO DE PARIS. Disponível em: http://www.alzheimer-europe.org/. Acesso em: 06 mai. 2014.

GELLER, Lisa N.; REICHEL, William. A doença de Alzheimer: aspectos biológicos. In: GALLO, Joseph J.; BUSBY-WHITEHEAD, Jan; RABINS, Peter V; SILLIMAN, Rebecca A.; MURPHY, John B. (Org.). Assistência ao idoso: aspectos clínicos do envelhecimento. Tradução de Carlos Alberto Gomes da Silva Junior... [et al.]. Rio de Janeiro: Guanabara Koogan S.A., 2001.

GEORGETOWN UNIVERSITY. Disponível em: http://pdba.georgetown.edu/constitutions/ constudies.html. Acesso em: 05 mai 2014.

GEP PORTUGAL (Gabinete de Estratégia e Planejamento de Portugal). Disponível em: http://www. gep.msess.gov.pt/seminarios/direitos_humanos/onu_mippa.pdf. Acesso em: 06 mai 2014.

INSTITUTOITALO-LATINOAMERICANO.Disponívelem:http://www.iila.org/index.php?lang=es. Acesso em 05 mai. 2014.

JACOB FILHO, Wilson; CHIBA, Toshio. Atendimento Multidisciplinar. In: CARVALHO FILHO, Eurico Thomaz; PALALÉO NETTO, Matheus (Org.). Geriatria: fundamentos, clínica e terapêutica. São Paulo: Atheneu, 2000.

MAL DE ALZHEIMER. Simetrias e assimetrias entre os planos nacionais de luta contra - mal de Alzheimer. Disponível em: www.maldealzheimer.wordpress.com/2012/centreforhealthybrainageing.com. Acesso em: 07 mai. 2014.

MORAES, Maria Celina Bodin de. O princípio da solidariedade. In: PEIXINHO, Manoel Messias; GUERRA, Isabella Franco; NASCIMENTO FILHO, Firly (Org.). Os princípios da Constituição de 1988. Rio de Janeiro: Lumen Juris, 2001.

NORONHA, Kenya Valéria Micaela; ANDRADE, Mônica Viegas. Desigualdade social em saúde entre idosos da América Latina. Disponível em: http://www.abep.nepo.unicamp.br/ SITE_EVENTOS_ALAP/PDF/ALAP2004_239.PDF. Acesso em: 01 mai. 2014.

PARAGUAI. Constituição da República. Disponível em: http://pdba.georgetown.edu/ Constitutions/Paraguay/para1992.html Acesso em: 05 mai. 2014.

PARLAMENTO EUROPEU. Disponível em: http://www.europarl.europa.eu/. Acesso em 06 mai. 2014.

PLANO DE AÇÃO DA ORGANIZAÇÃO PAN-AMERICANA DE SAÚDE 2009-2018. Disponível 
em: http://www.saudeidoso.icict.fiocruz.br/index.php?pag=polit. Acesso em: 06 mai. 2014.

PLANO FRANCÊS DE LUTA CONTRA O ALZHEIMER (2008-2012). Disponível em: http://www. sante.gouv.fr/le-plan-alzheimer-2008-2012,972.html. Acesso em: 07 mai. 2014.

QUEIROZ, Luísa Guimarães; GIOVANELLA, Ligia. Agência regional de saúde no Mercosul: arquitetura e temas. Revista Panamericana de Salud Publica. Washington, v.30, n.2, p. 182188 , agosto/2011.

RELATÓRIO PARLAMENTO EUROPEU A7-0366/2010. Disponível em: http://www. europarl.europa.eu/sides/getDoc.do?pubRef =-//EP//TEXT+REPORT + A7-20100366+0+DOC+XML+V0//PT. Acesso em: 06 mai 2014.

RESOLUÇÃO PARLAMENTO EUROPEU DE 19.01.2011 (texto P7-TA (2011)0016). Disponível em: http://www.europarl.europa.eu/sides/getDoc.do?pubRef=-//EP//TEXT+REPORT+A72010-0366+0+DOC+XML+V0//PT. Acesso em: 06 mai 2014.

REVISTA CHILENA DE SALUD PUBLICA. Disponível em: http://pt.scribd.com/doc/144665136/ Revista-Chilena-de-Salud-Publica-Vol-17-No-1-2013. Acesso em: 06 mai. 2014.

SCHOUERI JUNIOR, Roberto; RAMOS, Luiz Roberto; PAPALÉO NETTO, Matheus. Crescimento populacional: aspectos demográficos e sociais. In: CARVALHO FILHO, Eurico Thomaz; PALALÉO NETTO, Matheus (Org.). Geriatria: fundamentos, clínica e terapêutica. São Paulo: Atheneu, 2000.

SISAP IDOSO: Sistema de Indicadores de Saúde e Acompanhamento de Políticas do Idoso. Leis, políticas e portarias. Disponível em: http://www.saudeidoso.icict.fiocruz.br/index. php?pag=polit. Acesso em: 05 mai. 2014.

STUCCHI, Cláudio. A falta de políticas públicas para idosos com demência. Disponível em: $\quad$ http://www.previnerconsultoria.com.br/index.php/component/content/article/47artigos-do-terceiro-setor/119-artigo-a-falta-de-politicas-publicas-para-os-idososinstitucionalizados-que-sofrem-com-demencia.html. Acesso em: 01 mai. 2014.

URUGUAI. Constituição da República. Disponível em: http://pdba.georgetown.edu/ Constitutions/Uruguay/uruguay04.html Acesso em: 05 mai. 2014

Recebido em: set/2014

Aprovado em: mar/2015 